\title{
Effects of restraint on open-field activity, shock avoidance learning, and gastric lesions in the rat
}

\author{
JACKIE LANUM, MICHAEL E. CAMPBELL, DENNIS W. BLICK, \\ JOSEPHINE KNOX, and THOMAS G. WHEELER \\ Systems Research Laboratories, Brooks Air Force Base, Texas
}

\begin{abstract}
Many rat studies of learned helplessness confound the stress of restraint with inescapable shock. In the present experiment, albino rats were held immobile for $0,2,8,14$, or $18 \mathrm{~h}$. Behavioral deficits were observed in an open-field activity maze and in two-way shuttlebox avoidance acquisition. In the activity maze, a sex $\times$ restraint interaction was observed for latency to leave the center square, ambulation, and frequency of center square crossing. Males were slower to leave the center square, had fewer ambulations, and crossed the center square less frequently than females. These effects were potentiated by restraint. Males reared significantly less than females, and restrained animals reared significantly less than nonrestrained animals. Restraint also significantly increased the frequency of grooming. On the avoidance tasks, a significant restraint $X$ trial block interaction indicated slower learning for restrained animals. The severity of the decrements increased with restraint duration. The presence of stomach lesions was positively correlated with stress duration and the severity of the behavioral decrement. The results indicate that restraint produces a variety of behavioral changes which may result in interpretive difficulties for helplessness studies that confound restraint and shock.
\end{abstract}

Much research on behavioral deficits following exposure to aversive and uncontrollable experiences (learned helplessness) involves pretreatments that confound exposure to shock with restraint (e.g., Crowell \& Anderson, 1981; Glazer \& Weiss, 1976; Jackson, Alexander, \& Maier, 1980; Ley \& Crow, 1979). Such procedures have been accepted largely on the basis of arguments by Maier (see Maier \& Seligman, 1976, pp. 21-22) that restraint is an insignificant part of helplessness pretreatment because it does not produce escape deficits in rats. There is, however, evidence that restraint can be an important factor. For example, Bracewell and Black (1974) found a large deficit produced by restraint.

There is some evidence that the effects of restraint stress are similar to the effects of more traditional helplessness-inducing procedures using shock. For example, both produce increases in plasma corticosteroids (Quirce, Odio, \& Solano, 1981; Weiss, 1970)

The research reported in this paper was conducted by personnel of Systems Research Laboratories under Contract F33615-80-C0603, Job Order 7757-05-43, with the USAF School of Aerospace Medicine, Aerospace Medical Division, AFSC, United States Air Force, Brooks AFB, Texas. The animals involved in this study were procured, maintained, and used in accordance with the Animal Welfare Act and the "Guide for the Care and Use of Laboratory Animals" prepared by the Institute of Laboratory Animal Resources, National Research Council. J. Lanum is now at the Department of Psychology, Kerrville State Hospital, Kerrville, TX 78028. Reprint requests should mailed to D. W. Blick, P.O. Box 35313, Brooks AFB, TX 78235. and gastric ulceration (Brodie \& Hanson, 1960; Glavin, 1980; Seligman \& Meyer, 1970; Weiss, 1970). Providing the opportunity for rats to respond during restraint (i.e., providing a means of control) decreases the number of gastric lesions (Guile \& McCutcheon, 1980). Predictable restraint sessions reduce the magnitude and duration of plasma changes (Quirce et al., 1981), just as predictable shock causes fewer gastric lesions than unpredictable shock (Seligman \& Meyer, 1970). Although these similarities between restraint and uncontrollable shock are recognized, the effects of restraint stress on behavior have only recently been studied (Grilly \& Dugovics, 1982). The extent to which these similarities include behavior is not clear, although Seligman (1975, p. 169ff) describes helplessness studies wherein the critical treatment variable was restraint.

It should be noted that some investigators have not found deficits resulting from restraint. For example, Maier, Albin, \& Testa (1973) found that neither restraint nor inescapable shock produced deficits in an FR-1 shock-escape task. However, Maier et al. (1973) restrained their subjects in a plastic tube, perhaps the most common method of restraint, whereas Bracewell and Black (1974) used a plastic harness that immobilized the rats from the shoulders back. The different constraints on mobility could account for some differences in results.

The present studies were conducted to determine whether behavioral phenomena similar to those produced by inescapable shock could be produced by re- 
straint. A variety of restraint procedures are available for use with rats. As mentioned above, Maier et al. (1973) used plastic tubes; Bracewell and Black (1974) used a plastic harness; and Glavin (1980) taped the animals to a board in a supine position with limbs outstretched. These procedures allow varying degrees of movement. We chose a compromise procedure, restraining the subjects in a screen tube, based on the method of Brodie, Hanson, Sines, and Ader (19621963). Shuttle escape-avoidance behavior in rats was measured after exposing them to varying degrees of uncontrollable restraint. Since overall activity level may influence escape-avoidance learning, and since learning deficits associated with uncontrollable stress may be mediated by decreasing activity (Anisman, de Catanzaro, \& Remington, 1978), subjects in the present experiment were tested in an open-field maze after restraint stress but before shuttle testing. The parameters of restraint were investigated in both male and female rats by varying the duration of immobilization (degree of stress). Following behavioral testing, the animals were sacrificed to determine the incidence of gastric lesions.

\section{METHOD}

\section{Subjects}

The subjects were 54 male and 54 female Sprague-Dawley rats obtained, at 72 days of age, from Harlan Institutes, Indianapolis. They had ad-lib access to food and water and were maintained on a 12-h-on/12-h-off light-dark cycle for 4 weeks prior to experimentation. Lights were turned on at 6:00 a.m. All animals were tested at the same time of day, between 9:00 a.m. and 11:00 a.m.

\section{Apparatus}

Activity testing was performed in two standard open-field mazes $3 \mathrm{ft}$ square with a $1-\mathrm{ft}$ wall height $(91.4 \times 91.4 \times 30.4 \mathrm{~cm})$. Nine $1-\mathrm{ft}$ $(30.4-\mathrm{cm})$ squares were marked on the maze floor. The maze was constructed of plywood painted with glossy white enamel for ease of cleaning between trials. The mazes were located in the center of a large room approximately $2.6 \mathrm{~m}$ beneath a bank of $40-\mathrm{W}$ fluorescent bulbs. Observers were seated on stools at opposite corners of each maze and were not informed of the treatment group to which the observer subjects were assigned. No obvious shadows were cast on the maze floor by either the observers or by the maze walls.

Avoidance testing was performed in three shuttleboxes modeled after Lafayette Instrument Company's "Modular Testing Unit 8500." The two compartments of each shuttlebox had a floor of stainless steel bars that could be electrified independently. The compartments were connected by an opening, and the weight of the rat on the floor grid closed a switch to indicate the subject's location. Small, dim incandescent lamps were located on the end walls of each chamber, and two brighter incandescent lamps were located in the ceiling of each compartment above Plexiglas diffusers. The top half of the front wall of the chamber was halfsilvered ("one-way") glass to allow the experimenters to observe the subject. The shuttleboxes were interfaced to a laboratory computer (NOVA 800) through a control panel (MANX, G. C. Controls, Inc.). The schedule and the duration of stimuli delivered to the rat were programmed, and the rats' responses were also recorded by the computer.

\section{Procedure}

Every animal was handled and weighed once each day for 5 days. At approximately 100 days of age, 9 male and 9 female sub- jects were assigned randomly to each of the experimental conditions. Eighteen male and $\mathbf{1 8}$ female subjects served as controls. The groups were defined by the number of hours of restraint stress received: $0,2,8,14$, or $18 \mathrm{~h}$. Half of the control subjects ( $0 \mathrm{~h}$ restraint) were tested on the first day of the sequence and half on the last day. The remaining groups were tested in the following sequence: $18,2,14$, and $8 \mathrm{~h}$. The sequence of groups, tested on separate, consecutive days, was determined by a random process.

All groups were deprived of food for $24 \mathrm{~h}$ and of water for $18 \mathrm{~h}$ before testing. Each animal was subjected to restraint stress by being wrapped in screen wire for the prescribed number of hours prior to testing. This was accomplished by placing the rat on a piece of hardware cloth near the edge and rolling it into a tube that surrounded the rat. Sheets of 1.6- $\mathrm{mm}$ aluminum hardware cloth approximately $45 \mathrm{~cm}$ long were used to restrain the subjects. The ends of the screen wire tube were then twisted and secured with 20ga galvanized wire. Care was taken to wrap the screen wire tight enough for the subject not to be able to turn around but not tight enough for the animal to be compressed or twisted into an abnormal position. Each wrapped animal was placed, ventral side down, in a plastic tray. Because of the potential for stress communication through pheromone production, experimental subjects were always restrained in a separate room and never returned to the colony. The temperature in the room was maintained at $21^{\circ} \mathrm{C}$. By the same logic, experimental and control animals were never tested on the same day. The apparatus was water-sponged after each animal was tested. Additionally, the apparatus was washed with alcohol and allowed to dry overnight to minimize the odor transfer between groups.

All subjects were unwrapped and tested at the same time every day. This meant that subjects in different restraint groups were wrapped at different times of day, making them variably susceptible to restraint-induced gastric lesions (Ader, 1967). The alternative was to restrain all groups at the same time of day and release and test them at various times of day. The procedure chosen was deemed the lesser of two evils for the present purposes, since learning and memory have been shown to be vulnerable to chronological effects (Holloway \& Wansley, 1973).

Prior to testing in the activity maze, each animal was kept in a transport cage for $10 \mathrm{~min}$ with access to water. Then each animal was placed in the center square of the open-field maze, and the following data were recorded independently by two observers with scoring forms, pencils, and stopwatches for $5 \mathrm{~min}$ : (1) latency to leave the center square, (2) total number of lines crossed (ambulations), (3) number of center square crossings, (4) number of grooming episodes, (5) number of rearing episodes, and (6) number of fecal boli excreted. Interobserver reliability was high, with differences averaging less than $4 \%$. Therefore, the responses recorded by the two observers were averaged for subsequent analysis.

After activity testing, each animal was taken (via a transport cage) to an adjacent room for escape-avoidance testing. Escapeavoidance testing occurred in a darkened room and was preceded by a 5-min adaptation period in the shuttle chamber prior to the first trial. Four groups of 10 males each were tested in a pilot study to determine whether activity testing affects escape-avoidance learning. Two groups were restrained for $18 \mathrm{~h}$ and two were unrestrained. One group of restrained and one group of unrestrained rats were tested in the activity maze prior to escape-avoidance training. No significant differences associated with presence or absence of activity testing were observed among these groups $[F(3,37)=.67, p>.05]$, so no further attempts were made to dissociate activity testing from escape-avoidance testing.

Small end-wall lamps were on during the adaptation period and allowed the experimenter to observe the rat. Overhead lamps on each side of the chamber were programmed to be the primary CS, since they were brighter than the end-wall lamps. The program consisted of a 5-sec CS interval during which both the overhead and end-wall lamps flashed at a $2-\mathrm{Hz}$ rate in the side of the chamber where the rat was located. If the rat did not move to the other compartment of the shuttlebox, a US consisting of a pulsed (30- 
msec duration) .2-mA shock was administered at a $2-\mathrm{Hz}$ rate (synchronous with the light flashes) until the animal moved to the other compartment or until $15 \mathrm{sec}$ had elapsed. The CS (and the US, if present) terminated when the animal moved to the other compartment. If a rat stood in the doorway with feet on both grids, shock was briefly delivered to both grids in sequence and the CS was delayed 10 sec. CS-CS intervals were selected randomly from a range of 25 to $55 \mathrm{sec}$ with a mean of $40 \mathrm{sec}$. Each animal received 60 trials. Latency to respond from CS onset was recorded for each trial. A 20-sec latency was scored if an animal failed to respond. The trials in each session also were categorized and counted as (1) a failure to respond (no response for the 20-sec CSUS duration), (2) an escape (response during the US), or (3) an avoidance (response during the CS).

Within $1 \mathrm{~h}$ following avoidance testing, each animal was sacrificed (Halothane overdose). The stomach was removed, opened, and examined for lesions, which were specified by the number of approximate length.

\section{RESULTS}

\section{Activity}

Each of the six measures from the activity maze (latency to leave the center square, ambulations, rearings, center square crossings, groomings, and fecal boli) was analyzed as a $2 \times 5$ (sex $\times$ restraint time) factorial analysis of variance. For significant interactions, Dunnett's procedure was used to compare each restraint group (within each sex) to its unrestrained control group. The results of these multiple comparisons are indicated in Figure 1.

These data generally indicate that restraint significantly changed the activity of animals, with the greater changes generally occurring with longer restraint times. Since all animals had been food deprived for $18 \mathrm{~h}$ before the observation took place, the fecal boli were so infrequent that this measure was not useful.

Figure 1, upper left panel, shows latency to leave the center square for the two sexes as a function of duration of restraint. The sex $\times$ restraint interaction was significant $\left[F(4,98)=2.86, p<.05, \omega^{2}=.05\right]$ because males were much slower to leave the center square after 8 or $14 \mathrm{~h}$ restraint. The main effects for sex and restraint also were significant $[F(1,98)=$ $10.21, \mathrm{p}<.002, \omega^{2}=.07 ; \mathrm{F}(4,98)=4.01, \mathrm{p}<.005$, $\omega^{2}=.09$, respectively]. Females did not have increased latencies with increased restraint duration.

The middle left panel of Figure 1 presents the ambulation data for the two sexes after varying duration of restraint stress. The sex $\times$ restraint interaction was significant $\left[F(4,98)=4.05, p<.005, \omega^{2}=.06\right]$. In females, the restraint had no effect at $2 \mathrm{~h}$ duration, but reduced activity by increasing amounts as restraint duration increased. For males, there was also no effect at $2 \mathrm{~h}$ of restraint. A large reduction in ambulation by males occurred after $8 \mathrm{~h}$ of restraint, but longer durations did not appear to increase this effect. The main effects for sex and restraint also were significant $\left[F(1,98)=30.33, p<.0001, \omega^{2}=.13\right.$; $\mathrm{F}(4,98)=18.01, \mathrm{p}<.0001, \omega^{2}=.31$, respectively $]$.
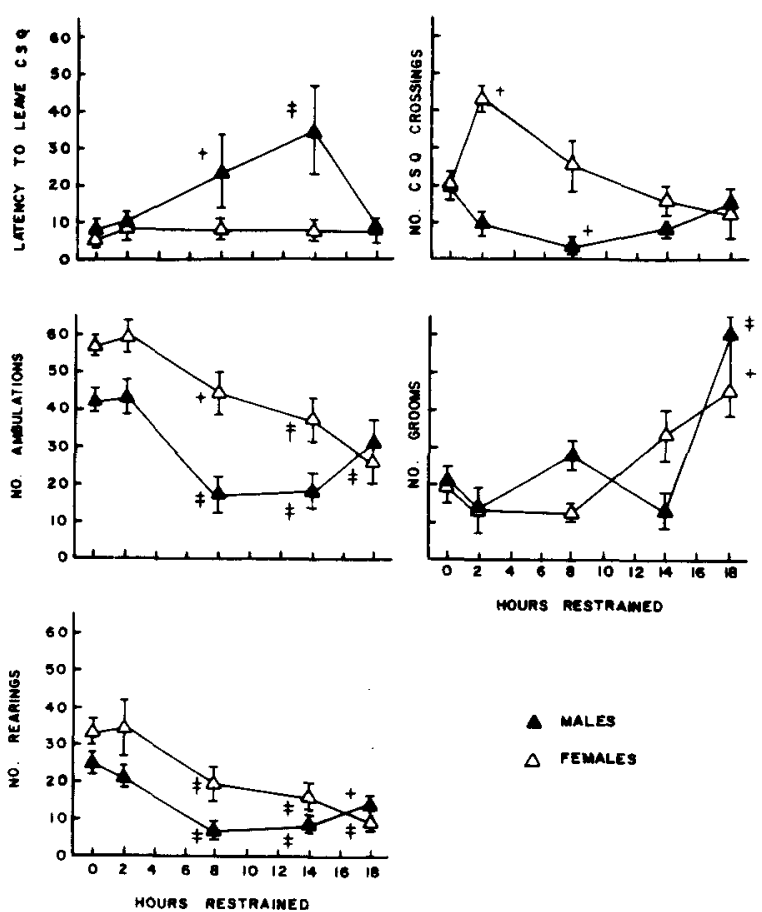

HOURS RESTRAMED

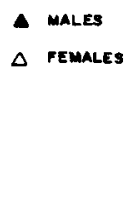

Figure 1. The mean performance $( \pm$ SEM) in the activity maze during a 5 -min period for male and female rats following $1,2,8$, 14 , and 18 h of restraint. Dunnett's procedure was used for each sex to test for differences between the unrestrained control group and the various restraint groups. Differences significant at $a=.05$ are indicated by a single dagger ( $\dagger$ ); differences significant at $\alpha=$ .01 are indicated by double daggers $(\$)$.

The data for rearing are illustrated in the lower left panel of Figure 1. The sex $\times$ restraint interaction was not significant. Significant main effects were observed for $\operatorname{sex}\left[F(1,98)=13.14, p<.0005, \omega^{2}=.06\right]$ and restraint $\left[\mathrm{F}(4,98)=19.4, \mathrm{p}<.0001, \omega^{2}=.37\right]$. Females were more active than males. Restraint reduced rearing, with the maximal effects occurring after $8 \mathrm{~h}$.

The upper right panel of Figure 1 shows the mean number of times the rats crossed the center square of the activity maze. The sex $\times$ restraint interaction was significant $\left[F(4,98)=4.28, p<.005, \omega^{2}=.09\right]$. Both sex and restraint were statistically significant $[F(1,98)$ $=17.53, \mathrm{p}<.0001, \omega^{2}=.11 ; \mathrm{F}(4,98)=3.05, \mathrm{p}<.03$, $\omega^{2}=.06$, respectively]. Females restrained for $2 \mathrm{~h}$ crossed the center square significantly more often than did controls. Males restrained for $8 \mathrm{~h}$ crossed the center square significantly less often than did controls.

Finally, Figure 1, middle right panel, also shows grooming as a function of restraint stress. No significant sex effect or sex $\times$ restraint interaction was found, although the main effect of restraint was significant $\left[F(4,98)=6.65, p<.0001, \omega^{2}=.17\right]$. The major change in grooming associated with restraint is the increase seen at $18 \mathrm{~h}$.

In summary, the data from the open-field maze 
present a fairly consistent pattern. Restraint disrupted behavior in the open-field maze and exacerbated sex differences, although the performance of males and females, following $18 \mathrm{~h}$ of restraint, was similar to that of controls. The males' behavior was inhibited most after 8 or $14 \mathrm{~h}$ of restraint. Females experienced a gradual increase in debilitation with increased restraint time.

\section{Escape-Avoidance}

The computer automatically recorded shuttlebox latencies by taking the difference between times of light onset (CS) and the rat's response of moving to the opposite compartment of the shuttlebox, where his weight on the grid closed a microswitch. This latency should be distinguished from the latency to leave the center square of the activity maze described above. Latency to respond following the CS was recorded for each subject, and was averaged across six blocks of 10 trials each. Analysis was made by means of a split-plot factorial (SPF 25.6, after Kirk, 1968) analysis of variance (main effects of sex, restraint, and block of trials).

The restraint group $\times$ trial block interaction was significant $\left[F(20,485)=2.72, p<.0001, \omega^{2}=.01\right]$ and is represented by the learning curves for each group of animals in Figure 2. Latencies for the 0 - and 2-h restraint groups decreased over blocks of 10 trials, whereas latencies for the 8-, 14-, and 18-h-restraint groups remained the same or first increased and then decreased after the third trial block. The significance of these trends was verified by decomposing the interaction into linear (n.s.), quadratic $[F(4,97)$ $\left.=5.58, p=.0004, \omega^{2}=.01\right]$, and cubic $[F(4,97)=$ $\left.5.29, \mathrm{p}=.0007, \omega^{2}=.01\right]$ components. The significant quadratic trend indicates a general tendency toward a typical negatively decelerated learning curve, the rate of change of which is determined by

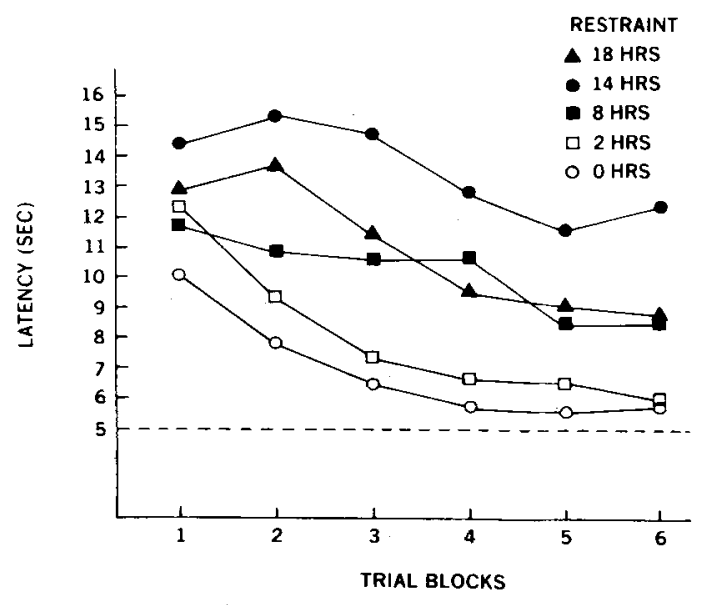

Figure 2. The mean escape/avoidance latencies across blocks of 10 trials for rats subjected to $0,2,8,14$, and $18 \mathrm{~h}$ of restraint stress. the grouping variable. The deceleration begins at different points in the training session for the different restraint groups. The significant cubic trend reflects the increase in response latency during the first two trial blocks followed by decreased latencies in subsequent trial blocks for the 14- and 18-h-restraint groups. These results indicate that learning occurred for all treatment groups, but learning was retarded for animals restrained $\mathbf{8 h}$ or longer.

Trend analyses were also performed on the data within each restraint group. The linear trend was significant for each group, verifying that learning occurred for each of the groups in Figure 2. The quadratic trend was significant for the control group $[F(1,12)=22.11, \mathrm{p}<.005]$, the 2 -h restraint group $[F(1,12)=15.76, p<.005]$, and the 18 -h restraint group $[F(1,12)=14.24, p<.005]$. A significant quadratic trend for learning data is generally taken to indicate an asymptote of performance. The cubic trend was significant for the 14-h-restraint group $[F(1,12)=13.85, p<.005]$ and for the 18-h-restraint group $[\mathrm{F}(1,12)=10.25, \mathrm{p}<.01]$. Figure 2 indicates that escape latencies in these two groups were longer in the second trial block than in the first and thereafter generaily decreased.

The restraint group main effect was significant $\left[F(4,97)=12.38, \mathrm{p}<.0001, \omega^{2}=.21\right]$. The trial block main effect was also significant $[F(5,485)=50.73$, $\mathrm{p}<.0001, \omega^{2}=.09$ ], confirming that learning did occur as response latencies decreased across trial blocks. These main effects were not evaluated further, since the restraint group $\times$ trial block interaction was significant (see above).

The data were separated into three mutally exclusive response categories (fail to respond, escape, and avoid) for additional analysis. An analysis of variance was performed for each of these measures. Figure 3 shows the average number of failures, escapes, and avoidances of each group. Restrained animals had significantly more failures to respond $\left[F(4,97)=8.20, p<.00001, \omega^{2}=.24\right]$ and fewer avoidances $\left[F(4,97)=8.14, p<.00001, \omega^{2}=.23\right]$. Restrained animals in the 8-, 14-, and 18-h treatment groups were more likely not to respond than control animals were. If the restrained animal did respond, that response was less likely to be an avoidance.

In Figure 3, there is an inverse relationship between avoidance responses and failures to respond. There were no significant differences in numbers of escape responses as a function of experimental treatment. Since large systematic increases in failures to respond were concomitant with decreases in avoidance, the overall number of escapes remained approximately the same. This is not merely an artifact of the classification system but shows that animals in all groups were capable of responding and were exposed to the escape contingency. 


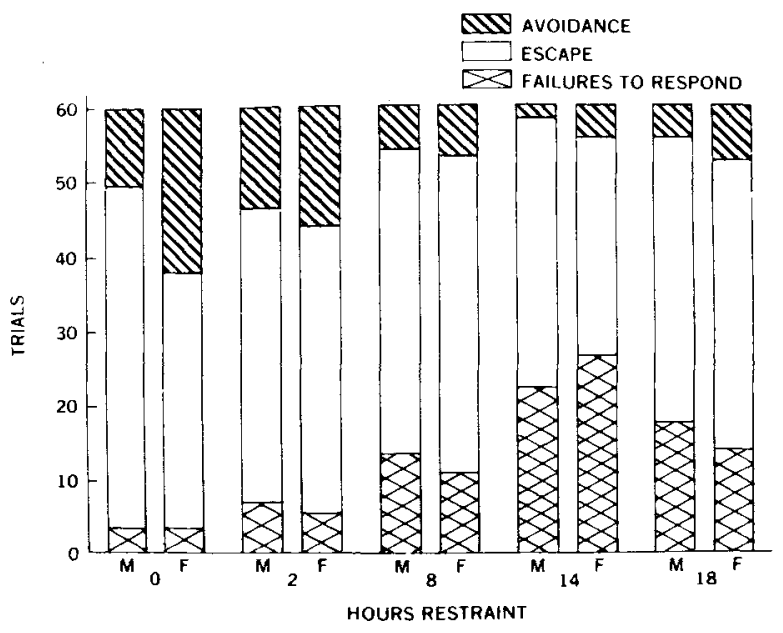

Figure 3. The mean numbers of avoidances, escapes, and failures to respond during 60 trials by male and female rats as a function of restraint stress duration.

Although we previously noted no significant differences in response latencies between sexes, an analysis by response category showed that females were more likely to avoid than males $[F(1,97)=3.86$, $\mathrm{p}<.05, \omega^{2}=.02$ ] (see Figure 3, note upper shaded portion of bars). This sex difference was most pronounced in the control animals; however, the interaction between sex and restraint condition was not significant for this measure.

Restraint stress produced decrements in two-way shuttlebox avoidance conditioning. When compared with controls, stressed rats had longer escape-avoidance latencies, failed to respond more often, avoided shock less frequently, and learned more slowly.

\section{Gastric Lesions}

Following behavioral testing, the animals were sacrificed and their stomachs were examined, grossly and microscopically, for lesions.

A stomach lesion typically consisted of an erosion of the first mucosal layer of the glandular fundus of the stomach. Histological examination of several lesions showed breakage of small capillaries and accompanying hematomata. The size of the lesions varied from pinpoint to approximately $2 \mathrm{~mm}$.

An analysis of variance of the number of lesions in each group showed a significant main effect for the restraint treatment $[F(4,98)=7.54, p<.0001$, $\left.\omega^{2}=.20\right]$. Differences among groups were examined using Dunn's procedure. The 14- and 18-h groups were significantly different from the others $\left(\mathrm{d}_{0.1}^{\prime}=.8\right.$; $\left.\mathrm{d}_{.05}^{\prime}=.64\right)$. The number of lesions increased with the number of hours of restraint stress, but the slight differences between the number of lesions at 14 and $18 \mathrm{~h}$ of restraint may indicate an asymptotic level of effect (Figure 4). Approximately $45 \%$ of the $14-$ and 18 -hrestrained animals had gastric lesions, whereas only $5 \%$ of the control and 2-h-restrained animals showed evidence of gastric erosion. There was no sex effect on gastric ulceration.

\section{Relationships Between Lesions and Behavior}

A Spearman rank order correlation coefficient was computed for comparison of the numbers of lesions and each of the behavioral measurements ( 5 categories of activity maze performance, numbers of avoidances, escapes, failures to respond, and avoidance latencies). Each group ( 5 stress groups $\times 2$ sexes $=10$ groups) was ranked from highest to lowest according to group mean in each behavioral category. Group rank in each behavioral category was then correlated with the group ranks for mean number of ulcers.

In general, there was a strong relationship between the behavioral measures and the presence of lesions (see Table 1). Groups of animals with greater numbers of lesions showed altered behavior in the activity maze, with fewer ambulations and rearings and more grooming episodes. In the shuttlebox, animals with more lesions tended to have more failures to respond, fewer avoidances, and longer overall response latencies.

\section{DISCUSSION}

This experiment demonstrates behavioral deficits resulting from restraint stress. In particular, escapeavoidance behavior was disrupted in a graded fashion. Latency to escape shock increased with duration of restraint. This effect does not appear to be due entirely to decreased activity associated with motor deficits. While activity was lower in some categories of open-field behavior (especially ambulation and rearing), these behaviors may have been displaced by increased grooming. Also, because the mean number of escape responses in the shuttle task did not change significantly as a function of restraint (Figure 3), motor deficits did not disrupt shuttle performance in any gross way.

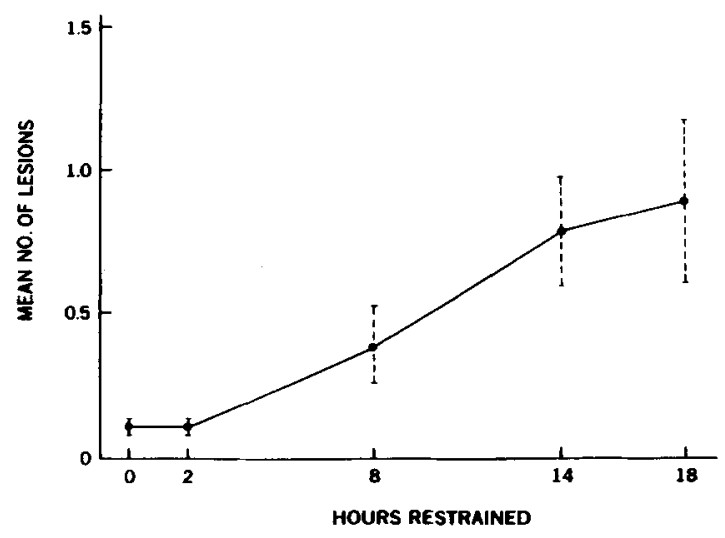

Figure 4. The mean number ( \pm SEM) of stomach ulcers seen following $0,2,8,14$, and $18 \mathrm{~h}$ of restraint stress. 
Table 1

Correlations and Associated Statistical Probabilities Between Behavioral Responses and the Number of Stomach Lesions

\begin{tabular}{ll}
\hline \multicolumn{1}{c}{ Behavior } & \multicolumn{1}{c}{$\begin{array}{c}\text { Correlation with } \\
\text { Ulcers }\left(\mathrm{r}_{\mathrm{s}}=\right)\end{array}$} \\
\hline $\begin{array}{l}\text { Activity Maze } \\
\text { Latency to leave center square }\end{array}$ & .2 \\
Ambulations & $-.57^{*}$ \\
Center square crossings & -.16 \\
Rearings & $-.61^{*}$ \\
Groomings & $.66^{*}$ \\
Shuttlebox & $.82^{* *}$ \\
Failures to respond & -.36 \\
Escapes & $-.65^{*}$ \\
Avoidance & $.75^{* *}$ \\
Latency after CS & \\
\hline
\end{tabular}

${ }^{*} p<.05 \quad * * p<.01$

Escape-avoidance latencies, evaluated over blocks of 10 trials, showed learning curves that began progressively later in the test session, depending upon the duration of restraint. That learning did occur for each group is supported by the significant trial block linear trends for each group. The control, 2-h restraint, and 18-h restraint groups also had significant quadratic trends, suggesting asymptotes of the learning curves. Why the severely stressed 18 -h group produced data similar to the less stressed control and 2-h groups on this and certain open-field measures (latency to leave the center square and center square crossing) is not clear.

The two most severely stressed groups (14- and 18$h$ restraint) also had significant cubic trends in the escape latency data over trial blocks. These trends indicate that the groups' escape latencies first became longer before getting shorter. That is, the animals not only failed to learn during the early trials of the test session, but actually performed more poorly before improving over the last half of the session. This was not due to a few animals in each group that failed to respond, since such failures were proportionately distributed among the animals. Most failures to respond did occur early in the test session. If escape-avoidance deficits following uncontrollable, aversive experience represent a truly general phenomenon, then this retardation in the onset of learning may partially resolve the dispute over whether such deficits are associative in nature or simply due to changes in activity level. The present results suggest that uncontrollably stressed animals experience associative deficits early in training which are at least partially overcome after several trials (Figure 2). Jackson et al. (1980, Figures 1, 3, 6) presented data for shockstressed rats that appear similar. Early in the escape training session, escape latencies and errors increased for more severely stressed animals; later in the session, learning began to occur and errors and latencies decreased toward asymptote.
Statistically significant sex differences in escapeavoidance latencies were not observed, although, like Bauer (1978), we found that females always produced lower mean latencies than males. Females had significantly more avoidances than males (Figure 3). These results suggest that females tolerate restraint stress better than males. Previous studies in our lab support this observation, inasmuch as $50 \%$ of males but only $10 \%$ of females succumbed after $24 \mathrm{~h}$ of restraint (Knox \& Campbell, 1980).

Sex and restraint condition did interact significantly on a number of activity measures. Males generally emitted fewer behaviors and had longer latencies than females for all restraint groups except the 18-h groups. In the latter groups, males had shorter latencies and made more responses than females. The general decrease in activity was offset somewhat by an increase in grooming behavior for both sexes. This increase was greater for longer restraint times and probably was precipitated by increased dishevelment, which results from long restraint. The general pattern of the interactions was an increased frequency of behavior for females after 2-h restraint and decreased frequency of behavior for males after 8-h restraint.

As others have reported (Brodie \& Hanson, 1960), we found significantly more gastric lesions with increasing restraint times. Gastric lesions were negatively correlated with ambulation and rearing in the open-field maze and with footshock avoidance in the shuttlebox. They were positively correlated with grooming, failure to escape shock, and latency to escape shock. In the present experiment, it is possible that physical discomfort associated with gastric ulceration contributed to the behavioral deficits that were observed.

Maier argues that restraint does not produce performance deficits on a shock-escape task (Maier, Albin, \& Testa, 1973; Maier \& Seligman, 1976) and is therefore not a confounding variable in studies of the effects of inescapable shock. The present results support the position of Bracewell and Black (1974) that restraint does disrupt shuttle acquisition. The general theory of learned helplessness would also seemingly predict the latter. The argument should run something like this: Uncontrollable and unpredictable restraint produces subsequent learning deficits, as does any uncontrollable and unpredictable stressor, because the animal learns that his response to escape the pain and discomfort of restraint are ineffective Therefore, subsequent exposure to escapable pain and discomfort produced by shock results in poor learning, since the previously learned response (i.e., don't struggle because it doesn't work) is incompatible with escape learning.

This experiment provides evidence for deficits in performance on a learning task resulting from re- 
straint stress. The deficits may have been mediated through changes in cognitive function, endocrine function, activity level, etc. However, they were not likely a result of motor deficits, since the mean number of escapes was similar for all groups. Future rathelplessness studies should take into account the confounded effects of restraint and shock on escapeavoidance behavior in previous studies.

\section{REFERENCES}

ADER, R. (1967). Behavioral and physiological rhythms and the development of gastric erosions in the rat. Psychosomatic Medicine, 29, 345-353.

Anisman, H., de Catanzaro, D., \& Remington, G. (1978). Escape performance following exposure to inescapable shock: Deficits in motor response maintenance. Journal of Experimental Psychology: Animal Behavior Processes, 4, 197-218.

BAUER, R. H. (1978). Ontongeny of two-way avoidance in male and female rats. Developmental Psychology, 11, 103-116.

Bracewell, R. J., \& Black, A. H. (1974). The effects of restraint and noncontingent preshock on subsequent escape learning in the rat. Learning and Motivation, 5, 53-69.

Brodie, D. A., \& Hanson, H. M. (1960). A study of the factors involved in the production of gastric ulcers by the restraint technique. Gastroenterology, 38, 353-360.

Brodie, D. A., Hanson, H. M., Sines, J. O., \& Ader, R. (1962-1963). Current research on gastric ulcers. Journal of Neuropsychiatry, 4, 388-408.

Crowell, C. R., \& Anderson, D. C. (1981). Influence of duration and number of inescapable shocks on intrashock activity and subsequent interference effects. Animal Learning \& Behavior, 9, 28-37.

Glavin, G. B. (1980). Restraint ulcer: History, current research and future implications. Brain Research Bulletin, 5, 51-58.

Glazer, H. I., \& Weiss, J. M. (1976). Long-term and transitory interference effects. Journal of Experimental Psychology: Animal Behavior Processes, 2, 191-201.

Grilly, D. M., \& Dugovics, J. P. (1982). Effects of immobiliza- tion stress on shock discrimination performance in rats. Physiology \& Behavior, 29, 1077-1081.

Guile, M. N., \& McCutcheon, N. B. (1980). Prepared responses and gastric lesions in rats. Physiological Psychology, 8, 480-482.

Holloway, F. A., \& W Ansley, R. (1973). Multiphasic retention deficits at periodic intervals after passive avoidance learning. Science, 180, 208-210.

Jackson, R. L., Alexander, J. H., \& Maier, S. F. (1980). Learned helplessness, inactivity, and associative deficits: Effects of inescapable shock on response choice escape learning. Journal of Experimental Psychology: Animal Behavior Processes, 6, 1-20.

KIRK, R. E. (1968). Experimental design: Procedures for the behavioral sciences. Belmont, CA: Brooks/Cole.

KNox, J., \& CAMPBELL, M. E. (1980). Helplessness and sex differences. Paper presented at the Ninth Annual Minority Biomedical Support Symposium, Atlanta, GA.

LEY, M. F., \& Crow, L. T. (1979). The effects of alcohol on learned helplessness. Physiological Psychology, 7, 387-390.

Maier, S. F., Albin, R. W., \& Testa, T. J. (1973). Failure to learn to escape in rats previously exposed to inescapable shock depends on nature of escape response. Journal of Comparative and Physiological Psychology, 85, 581-592.

Maier, S. F., \& Seligman, M. E. P. (1976). Learned helplessness: Theory and evidence. Journal of Experimental Psychology: General, 105, 3-46.

Quirce, C. M., Odio, M., \& Solano, J. M. (1981). The effects of predictable and unpredictable schedules of physical restraint upon rats. Life Sciences, 28, 1897-1902.

Seligman, M. E. P. (1975). Helplessness: On depression, development, and death. San Francisco: Freeman Press.

Seligman, M. E. P., \& Bengley, G. (1975). Learned helplessness in the rat. Journal of Comparative and Physiological Psychology, 88, 534-541.

Seligman, M. E. P., \& Meyer, B. (1970). Chronic fear and ulcers in rats as a function of the unpredictability of safety. Journal of Comparative and Physiological Psychology, 73, 202-207.

WEISS, J. M. (1970). Somatic effects of predictable and unpredictable shock. Psychosomatic Medicine, 32, 397-408.

(Manuscript received April 28, 1983; revision accepted for publication March 29, 1984.) 